\title{
Reconstruction of Palpebral-Cheek Defect Using an Anterior Bilobed Cheek Flap a New Reconstruction Technique about a Clinical Case
}

\author{
Eabdenbitsen Adil*, Mouzouri Mohammed, El amrani yasmine, El ayoubi Fahd, Ghailan Mohammed Rachid
}

Department of ENT and Maxillofacial Surgery Mohammed VI University Hospital OUJDA Morocco

\author{
DOI: 10.36348/SJMPS.2019.v05i09.010 \\ | Received: 29.08.2019 | Accepted: 05.09.2019 | Published: 29.09.2019 \\ *Corresponding author: Eabdenbitsen Adil
}

Abstract

The reconstruction of zygomatic defects is a challenge for de facial surgeon. We report in this paper a new technique of reconstruction using an anterior bilobed cheek flap. A 60-year-old man had developed a tumor on his left cheek. A biopsy revealed basal cell carcinoma. The ulcerative cancer was resected then we designed an anterior bilobed cheek flap to reconstruct the cheek skin defect. The postoperative clinical course was uneventful, and the flap showed a good take.

Keywords: Reconstruction, anterior bilobed cheek flap, zygomatic defects.

\begin{abstract}
Copyright @ 2019: This is an open-access article distributed under the terms of the Creative Commons Attribution license which permits unrestricted use, distribution, and reproduction in any medium for non-commercial use (NonCommercial, or CC-BY-NC) provided the original author and source are credited.
\end{abstract}

\section{INTRODUCTION}

The lateral cheek area is a good donor zone for the reconstruction of the soft tissue defect from the oral and the parotid-masseterine areas. When the soft tissue defect is significant, it's necessary to combine a lateral cheek flap and a retro auricular flap.

However, this skin tissue transposition causes an anterior movement of the pre-auricular capillary region and requires a skin graft at the level of the retro auricular donor area.

The cervico-facial bilobed flap can also cover the cheek area, but requires the presence of cutaneous laxity to close up the donor area $[1,2]$. The bilobed flap was described for the first time in 1918 to allow the reconstruction of nasal tip loss [3].

Zimmany [4] has popularized the bilobed flap for which the two lobes are separated by an angle and based on a common pedicle. Thus, in this clinical case, instead of the cervico facial flap, we used an anterior bilobed cheek flap for the reconstruction of palpebralcheek tissue defect.

Owing to our patient's skin laxity, the bilobed flap was the most appropriate flap for this new reconstruction technique of palpebral-cheek defect, which is describes below in this work.

\section{CASE REPORT}

A 60-year-old patient, with no notable pathological antecedents, developed a tumor of the left palpebral cheek area since 4 years. This tumor has gradually increased in volume.

- A biopsy with anatomopathological study revealed a Basal Cell Carcinoma.

- The Computed Tomography Scanner showed infiltration of the soft tissues without bone involvement or orbital invasion.

- The clinical examination does not show any cervical lymphadenopathy.

- A surgical resection was performed with margins of $7 \mathrm{~mm}$.

- A normal periorbital fat was observed in deep cuts.

- The surgical resection caused a soft tissue defect estimated at $6.5 \mathrm{~cm} \times 7.4 \mathrm{~cm}$ (Figure 1).

- The reconstruction is performed using an anterior bilobed flap cheek

- The upper lobe is limited from the lower side by the nasolabial fold and the flap was taken from the area under the Superficial Muscular Aponeurotic System (SMAS).

- The second lobe was taken from the submandibular area. Its pedicle is located in front of the mandibular angle and attached to the platysma muscle at the distal half of the flap to prevent damage of the facial nerve marginal branch (Figure 2)

- The flap was lifted and sutured with good surgical outcomes. 
- The palpebral reconstruction is planned and performed in a second step.

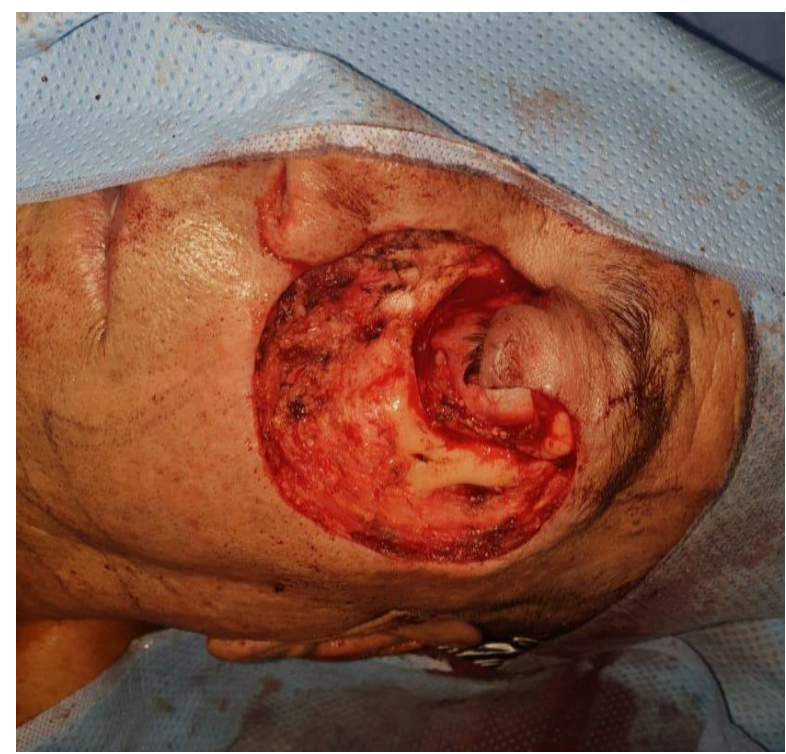

Fig-1: cheek skin defect after tumor resection

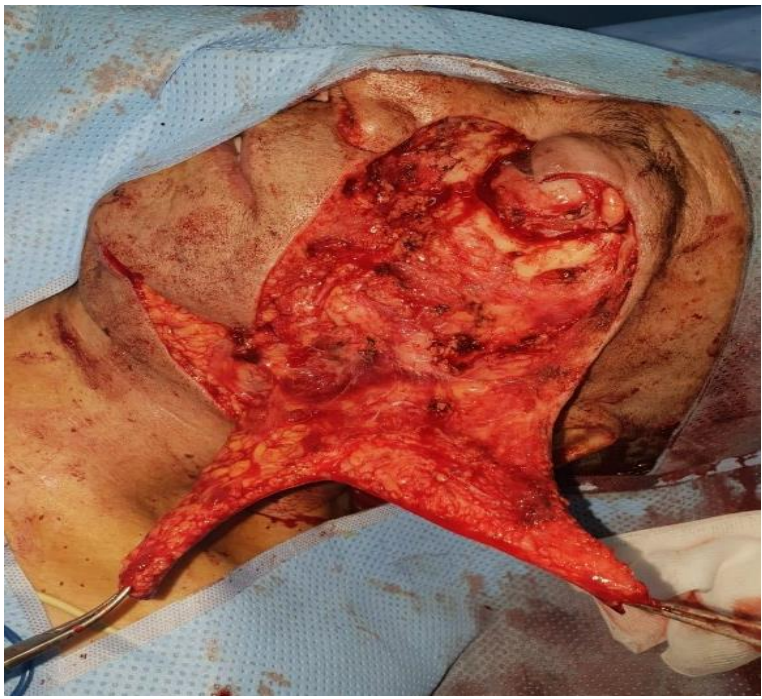

Fig-2: Picture of anterior bilobed cheek flap

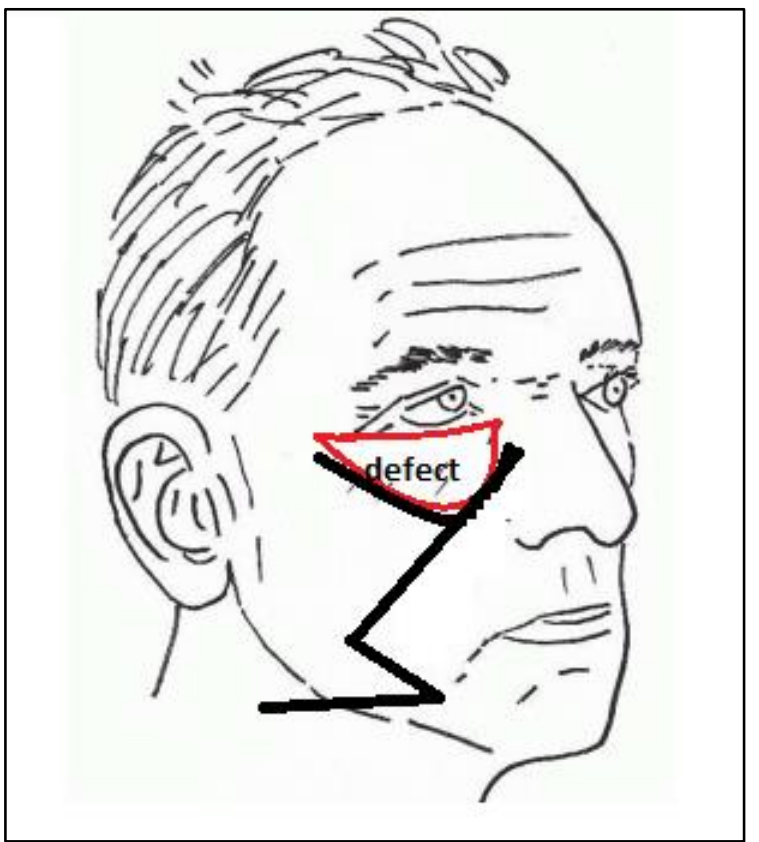

Fig-3: Schematic of the anterior bilobed cheek flap

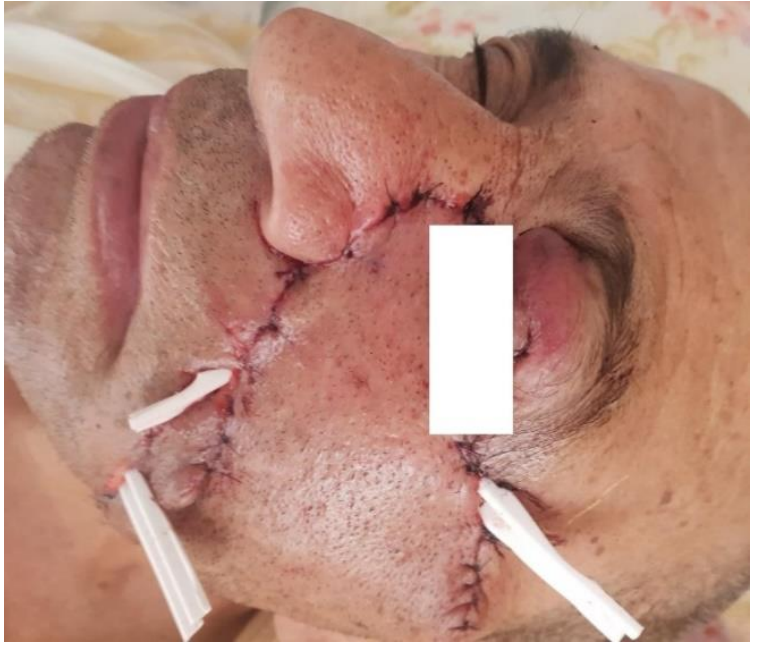

Fig-4: Postoperative picture of the patient after defect reconstruction

\section{DISCUSSION}

Extensive facial soft tissue defect can be reconstructed by different processes including advancement flaps or bilobed flaps. The combination of a pre-auricular and retro auricular flap in a bilobed flap can provide enough tissue to repair a loss of external soft tissue [5, 6].

The retro auricular donor area have to be covered in this case by a skin graft. When the defect extends towards the upper eyelid, as in this case, it is difficult for the retro auricular flap to cover the preauricular donor area. The second disadvantage of this process is the forward displacement of the pre-auricular capillary region. 
Considering all of these parameters, we used an anterior cheek bilobed flap to reconstruct a large tissue defect of zygomatic cheek's soft parts.

The first lobe is taken from the cheek area and the second lobe from the submandibular soft tissues with a direct suture of the donor area thanks to the tissue laxity of our patient (Figure 3).

The palpebral reconstruction is planned and performed in a second operative step. The cervico facial flap can also cover the soft tissue defect from the mouth area $[1,2]$. However, this flap is particularly suitable for elderly patients because of cervical tissue laxity that allows the suture of the donor area without tension.

Concerning younger patients, a neck skin graft may be necessary to avoid excessive pulling on the lower eyelid. The anterior bilobed cheek flap can cover the soft tissue defect without resorting to a skin graft. From this result, we estimate that the anterior bilobed flap is a good surgical technique of reconstruction, which is rarely used in facial reconstructive surgery.

\section{REFERENCES}

1. Kaplan, I. S. I. D. O. R. E., \& Goldwyn, R. M. (1978). The versatility of the laterally based cervicofacial flap for cheek repairs. Plastic and reconstructive surgery, 61(3), 390-393.

2. Goldwyn, R.M.(1998). Cervicofacial skin flap to the cheek. In: Strauch B, Vasconez LO, HallFindlay EJ, eds. Grabb's Encyclopedia of Flaps. $2^{\text {nd }}$ ed. Philadelphia, Pa.: Lippincott-Raven; 418-420.

3. Matarasso, A., Strauch, B. (1998). Bilobed nasal skin flaps. In: Strauch B, Vasconez LO, HallFindlay EJ, eds. Grabb's Encyclopedia of Flaps. 2nd ed. Philadelphia, Pa.: Lippincott-Raven, 139141

4. Zimmany, A.(1953). The bilobed flap. Plast Reconstr Surg, 1953: 424-434.

5. Washio, H.(1972). Further experiences with the retroauricular-temporal flap. PlastReconstr Surg, 162-162.

6. Dias, A.D, Chhajlani, P. (1987). The post- and retro-auricular scalping flap (the PARAS flap). Br J Plast Surg, 40: 360-366. 